\title{
PAISAGENS DO INTERIOR: REGIÕES DE MEMÓRIA E OUTROS LIRISMOS NA PRIMEIRA POÉTICA DE HELENA KOLODY (1941-1951)
}

\section{COUNTRYSIDE LANDSCAPES: PLACES OF MEMORY AND OTHER LYRICISM IN FIRST HELENA KOLODY POETIC (1941-1951)}

\section{Marco Aurélio de Souza*}

Resumo: Este artigo se propõe a analisar as construções paisagísticas de um grupo de poemas de Helena Kolody, contribuindo assim para o enriquecimento da história literária paranaense e da fortuna crítica ligada à poetisa. Partindo de considerações teóricas que apresentam as paisagens como construções culturais subjetivas, a análise da primeira poética kolodyana-suas três primeiras obras-revela uma cultura paisagística e de relação com a natureza característica que se conecta com a realidade do Estado do Paraná no início do século XX, influenciando gerações posteriores de artistas e intelectuais paranaenses. Assim, o trabalho apresentado se vincula não apenas aos estudos literários, mas também às pesquisas em História das Paisagens, área organicamente interdisciplinar, na qual o trânsito entre diferentes campos de conhecimento é favorecido e indispensável.

Palavras-chave: Paisagem. Helena Kolody. Literatura paranaense.

Abstract: This article is going to analyze the landscape constructions of some poems by Helena Kolody, aiming at the enrichment of paranaense literary history and literary criticism related to this poet. Starting with the theoretical discussions which present the landscapes as subjective cultural constructions, the analyses of the first kolodyan poetic - her three first books - reveals a landscape culture and its relation to nature, characteristic that is part of Paraná state in the beginning of $20^{\text {th }}$ century, influencing future generations of paranaense artists and intellectual people. As a result, this investigation refers not only to literary studies, but also to the research on History and Landscape, organically interdisciplinary area in which the approach to two different fields of knowledge is favored and essential.

Keywords: Landscape. Helena Kolody. Literature from Paraná.

\footnotetext{
* Mestrando em Linguagem, Identidade e Subjetividade pela Universidade Estadual de Ponta Grossa (UEPG). Email: messiasindeciso_@hotmail.com.
} 
A paisagem és tu,

Pois teu olhar somente alcança a perceber O que reflete a luz que emana de teu ser.

$\left(\right.$ Helena Kolody) ${ }^{1}$

A professora oferece a seu aluno um livro estranho, livro de versos - que tipo de pessoa compra e lê livros de versos? O aluno, gordinho e bagunceiro, vê a obra com desdém. Detesta poesia. Não tanto pelo conteúdo ou pelas imagens, mas pelo acompanhamento desconfortável que se chama declamar. É que a professora, crente no poder das letras e na função pedagógica da oralidade, organiza periodicamente na escola em que leciona um dia de declamação de poesias. Neste dia, tudo que se mostra é um circo de vaidades e vergonhas. E que tipo de pessoa gosta de declamar poesia?

Devidamente orientado, o piá descobre que tem em mãos o livro de uma poetisa de sua terra, que deu aulas em sua cidade natal, exatamente como a professora postada em frente ao quadro negro. Mas isto não importa para aquela criança despreocupada com a vida, já que fronteiras, bandeiras e hinos não fazem parte de seu tímido repertório infantil. Para ele, a importância conferida por toda aquela gente à senhora fazedora de versos é certamente descabida. Ver importância nos políticos e nos policiais é uma coisa - mas numa escritora de versos? A senhora, de nome Helena Kolody, era insignificante para seu mural de referências culturais, permeado por desenhos animados, gibis e videogames. Um curto poema bastava (e era o ideal) para cumprir rapidamente a atividade declamatória, desdenhada pelo gordinho, que era eu. Foi por preguiça, portanto, que conheci o haikai.
Hoje, se devaneio sobre o ser paranaense, sobre a terra que piso todos os dias, as imagens que me vêm à mente são todas de natureza, são paisagens do interior. Talvez por idealização mítica de um passado que nunca existiu. Talvez por influência dos quadros e das pinturas bucólicas que habitavam as paredes de minha infância, tão comuns em minha casa e nas casas da vizinhança, os quais hoje já não vejo e já não tenho mais. Talvez ainda porque os ecos daqueles versos lidos na escola, versos de Helena Kolody, fizeram brotar em minha memória uma região pura, uma região verde que não era minha casa, mas que poderia ser. Quando me dizem Paraná, não me lembro dos prédios curitibanos, nem do concreto velho ponta-grossense, nem das plantações imensas da Lapa ou da urbanidade planejada das cidades do Paraná moderno. Não me lembro, sobretudo, de minha cidade natal, Rio Negro, mas de um lugar que se confunde com ela, que está nos versos de uma poeta falecida - chamada por Leminski de padroeira da poesia paranaense. É um lugar cheio de rios, pássaros, campos e pinheiros. É um lugar que não habito - é ele quem habita em mim.

\section{O CONCEITO DE PAISAGEM NAS HUMANIDADES}

O espaço percebido pela imaginação não pode ser o espaço indiferente entregue à mensuração e à reflexão do geômetra. É um espaço vivido. E vivido não em sua positividade, mas com todas as parcialidades da imaginação.

$(\text { Bachelard })^{2}$ 
Seja pelo privilégio concedido ao olhar na hierarquia dos sentidos da contemporaneidade, seja pela tradição empirista da realidade "como coisa dada" - teleológica, autoexplicativa - presente na ciência moderna, as imagens, cotidianamente, são entendidas como o próprio referente a que buscam representar. Mesmo que a arte moderna tenha nos provocado com cachimbos que não são exatamente cachimbos, persiste ainda no senso comum a ideia de que as imagens reproduzem a realidade tal como ela é. Como afirma Queiroz Filho:

Um desenho, uma fotografia, uma cena, não é a realidade. Nunca é a própria coisa que está lá, mas algo mediado. Basta imaginarmos o que está fora do enquadramento. Aliás, a própria idéia de quadro, nos sugere isso, uma escolha, um olhar sobre. Mesmo se pensarmos numa imagem de satélite, existe a escolha de onde se tirar a fotografia e dependendo da tecnologia utilizada, algumas cores são "privilegiadas" e, com isso, nossa sensação sobre aquilo que foi recortado pode ser uma, ou outra. (FILHO, 2007, p. 02).

O conceito de paisagem, pensado pelo conjunto das ciências humanas, pode nos auxiliar numa compreensão mais profunda daquilo que tomamos como real e que, traiçoeiramente, está sempre se distanciando desta realidade tida como objetiva e, contudo, nunca retirada consistentemente do campo das abstrações idealistas.

Por sua extensa área de abrangência, o estudo das paisagens se desdobrou, ao longo do século XX, em inúmeras aborda- gens, vinculadas a diferentes campos de conhecimento:

[...] da pintura de paisagens (um capítulo da história da arte) e do paisagismo (parte incorporada à arquitetura e urbanismo), o tema extrapolou para a geografia (seja física ou humana), para a ecologia (por conta do movimento ambientalista), para a história, para os estudos de cinema, e também para o turismo e a literatura, pois já se estuda a paisagem a partir de relatos de viajantes, e dos guias de viagens. (VIEIRA, 2006, p. 02).

A geografia, como disciplina de conhecimento que tem o conceito de paisagem na qualidade de pilar, nos brindou em sua caminhada específica com importantes esforços intelectuais na definição de paisagem e contribuições ao corpo teórico de sustentação do tema. Afinal, paisagem é o postal turístico, é tudo que o olho vê ou a imagem da natureza inviolada?

Cosgrove (1998), tentando limitar a abrangência desta resposta, considera a paisagem como uma leitura de mundo, uma construção mental que organiza o espaço (enquanto matéria bruta) e o compõe. E, como constructo, a paisagem carrega também as subjetividades do observador/compositor do fotógrafo, pintor, poeta; enfim, daquele que enuncia a paisagem. Na mesma direção, Queiroz Filho é quem novamente nos auxilia:

O desprendimento das folhas dos galhos de sua árvore, por exemplo, é uma coisa para o poeta, outra para o cineasta, outra 
para o pintor. Em cada um deles, nasce paisagem diferente. Ganhamos com essa multiplicidade que o homem tem para dizer das coisas, suas e da natureza. (FILHO, 2007, p. 03).

Bastante familiar aos geógrafos, o conceito de paisagem tem uma história relativamente recente dentro do campo da historiografia. Os historiadores, apropriando-se do conceito, dinamizaram sua funcionalidade, tornando-o ao mesmo tempo maleável e delimitado, o que é o mesmo que dizer: dotaram-no de historicidade. A reflexão de Simon Schama, porém, não se furta a considerar também o aspecto subjetivo e cultural intrínseco das paisagens:

[...] conquanto estejamos habituados a situar a natureza e a percepção humana em dois campos distintos, na verdade elas são inseparáveis. Antes de poder ser um repouso para os sentidos, a paisagem é obra da mente. Compõe-se tanto de camadas de lembranças quanto de estratos de rochas. (SCHAMA, 1996, p. 17).

Em outras palavras, as paisagens são construções culturais e, como tal, respondem aos valores, significados e filosofias determinados pelo espaço-tempo a que se relacionam. Por mais realista que uma paisagem se proponha, representada em palavras ou cores, nela estará sempre embutida a carga subjetiva de quem a representa e de quem a observa.

Em Paisagem e Memória, Schama busca revelar a antiguidade, a complexidade e a riqueza da tradição paisagística de deter- minadas culturas do ocidente. Partindo do pressuposto de que "nem todas as culturas abraçam natureza e paisagem com igual ardor" (SCHAMA, 1996, p. 25), e de que os mitos acerca da natureza possuem significados diversos em temporalidades e localidades distintas, o historiador analisa as paisagens construídas pela arte em diversos momentos da história do ocidente, sugerindo que os "hábitos culturais da humanidade sempre deixaram espaço para o caráter sagrado da natureza" (SCHAMA, 1996, p. 29).

Considerações oriundas dos departamentos de História e Geografia, o percurso apresentado, contudo, pode contribuir com as análises literárias, na medida em que a própria literatura é pensada como um dos veículos pelos quais as paisagens se criam e são comunicadas. Como veremos a seguir, a leitura dos poemas de Helena Kolody pode enriquecer as considerações de historiadores e geógrafos, e demonstram que, por meio de "camadas de lembranças”, entrelaçadas às representações regionais e tradições culturais próprias do contexto em que a escritora vivia, sua poética delimitou fronteiras, fundou e articulou espaços, mapeou lugares e regiões, falou sobre realidades ao mesmo tempo em que as constituiu textualmente ${ }^{3}$. Nos limites deste artigo, buscarei analisar as regiões de memória que brotam da primeira poética de Helena, realizando a crítica de

3 Sobre o relato como uma operação sobre os espaços e lugares, Michel de Certeau aponta para o caráter delimitador, criador de demarcações e fronteiras, que é próprio das narrativas. Estes relatos operantes, para o autor, possuem a função de fundar e articular os espaços, bem como constituem "uma imensa literatura de viagens, isto é, de ações organizadoras de áreas sociais e culturais mais ou menos extensas" (p. 190). Os poemas de Helena, neste sentido, podem ser entendidos como relatos literários. Ver: Certeau, 2011. 
suas paisagens e dos elementos naturais que são evocados pela poetisa, ora como metáforas, ora como pura contemplação. As regiões de memória - o conjunto das paisagens, por vezes contraditórias e/ou distantes no espaço e no tempo, esboçadas pela escritora - nos revelam particularidades de uma incipiente cultura paisagística/ artística/literária do Paraná na primeira metade do século $\mathrm{XX}$, enriquecendo nosso conhecimento histórico, geográfico e literário vinculado ao recorte contemplado.

\section{UMA PADROEIRA DA POESIA PARANAENSE}

Constantemente reconhecida pela história literária do Paraná como um dos grandes nomes das letras do Estado, Helena Kolody, nascida em Cruz Machado - PR, é considerada pela crítica como precursora da poesia paranaense contemporânea, "uma das primeiras a iniciar o itinerário da sintetização de linguagem e pensamento" (SOARES, 1997, p. 08), exercício presente, por exemplo, nos contos minimalistas de Dalton Trevisan e nos haikais de Alice Ruiz e Paulo Leminski. Este último, sintomaticamente, chegou mesmo a considerar Helena Kolody como pioneira da literatura modernista no Paraná, dominado ainda nos anos 1940 por expressões poéticas vinculadas ao movimento simbolista ${ }^{4}$.

Observando a biografia de Kolody, é possível identificar diferentes fases dentro de sua produção poética. Tanto no plano estético quanto no temporal, dois períodos distintos de sua obra são destacados por alguns de seus críticos. Publicados dentro de

4 Ver documentário Helena de Curitiba, dirigido por Josina Melo. Sobre a hegemonia cultural dos simbolistas no Paraná, ver: Oliveira, 2009. um intervalo de dez anos, Paisagem Interior, de 1941, Música Submersa, de 1945 e A Sombra no Rio, de $1951^{5}$, os três primeiros títulos de sua carreira literária, caracterizam-se pelo lirismo exacerbado e poemas longos (em sua maioria), em contraste com os títulos subsequentes, mais filosóficos e sintéticos. Esta nítida mudança pode ser compreendida por meio do hiato que separa A Sombra no Rio de Vida Breve, publicado apenas em 1965, quase 15 anos depois, portanto - tempo que, possivelmente, foi crucial no processo de amadurecimento literário da escritora.

O diálogo com sua poética que aqui é proposto ficará restrito às referidas três obras do primeiro momento de sua biografia. Não apenas a viabilidade de um recorte mais modesto - coerente com as possibilidades e a extensão de um artigo acadêmico - pesam em tal decisão, mas também a convicção de que as ideias e concepções de vida/arte tecidas e expressas nesta fase de amadurecimento poético nos mostram de forma mais acentuada as tensões e combinações estéticas e filosóficas que auxiliaram na construção de seu estilo, que acompanhou a escritora ao longo dos anos e dos poemas, conferindo à sua obra características singulares - uma identidade literária.

\section{VIAGEM NO ESPELHO, ALMA INQUIETA}

Ao longo de todo o período delimitado, Helena viveu - com interrupção apenas em 1944, quando prestou serviços na Escola de

5 Os três títulos podem ser encontrados na coletânea de obras completas intitulada Viagem no Espelho, a qual será utilizada para consulta nesta pesquisa. Ver: KOLODY, H. Viagem no Espelho. 5. ed. Curitiba: Editora da UFPR, 1999. 
Professores de Jacarezinho - na cidade de Curitiba, onde residia desde 1937. Contudo, as três obras estão cronologicamente próximas de períodos anteriores da experiência da escritora, quando esta residiu em cidades como Três Barras (onde passou a maior parte da infância), Rio Negro (cidade em que estudou o Curso Primário e também iniciou sua carreira de docente) e Ponta Grossa (foi professora da Escola Normal de Ponta Grossa de 1933 a 1937). Estas cidades, locais de moradia, lazer e trabalho, podem ser consideradas o itinerário e o mapa das lembranças kolodyanas, integrando um painel de referências espaciais da escritora. Evidentemente, muito se escapa deste precário mapeamento, contudo, como ponto de partida, podemos apontar tais localidades como fundamentais para a composição de suas regiões de memória. Como se verá adiante, a nostalgia e a memória são elementos essenciais da poesia de Kolody, e como tal, inserem nas paisagens poéticas da escritora lugares os quais fazem parte de seu repertório cultural - seja como antigas cidades-moradas, seja como referência oriunda da oralidade e do imaginário de seu grupo social.

Do ponto de vista estilístico, os três títulos podem ser considerados bastante ecléticos. Neles coexistem expressões de influência modernista - nas quais se constata a ausência de rima e métrica tradicionais (Vento da noite, ainda é cedo!/...e nem lavrei a terra agreste. $\left.{ }^{6}\right)$-, sonetos e versos brancos que flertam com o simbolismo (No limiar dos mundos ignorados,/Onde aportaram suas naves quietas,/Relembro a alma sonora dos poetas,/A alma sensivel dos predestinados. $\left.{ }^{7}\right)$, e

6 Trecho de "Advertência", publicado em A Sombra no Rio (KOLODY, 1999).

7 Trecho de "Poetas Mortos", publicado em Música Submersa (KOLODY, 1999). mesmo, a despeito da predominância dos poemas longos mencionada anteriormente, os haikais (Arco-íris no céu./ Está sorrindo o menino/Que há pouco chorou. ${ }^{8}$ )-forma poética cuja presença na literatura brasileira do período era escassa, e pode ser considerada como pioneira.

Como já ressaltado por muitos dos seus críticos, a nostalgia, revelada pelo trabalho com a memória e com o período da infância, é um tema recorrente de seus poemas. Referências a situações, lugares e pessoas surgem (re)criando poeticamente a trajetória pessoal da escritora. Exemplar neste sentido é o poema "Infância", publicado em A Sombra no Rio:

\section{Infância}

Aquelas tardes de Três Barras.

Plenas de sol e de cigarras!

Quando eu ficava horas perdidas

Olhando a faina das formigas

Que iam e vinham pelos carreiros,

No áspero tronco dos pessegueiros.

A chuva-de-ouro

Era um tesouro

Quando floria.

De áureas abelhas

Toda zumbia.

Alfombra flava

O chão cobria...

O cão travesso, de nome eslavo, Era um amigo, quase um escravo.

8 Poema "Arco-Íris", publicado em Paisagem Interior (KOLODY, 1999). 
Merenda agreste:

Leite crioulo,

Pão feito em casa,

Com mel dourado,

Cheirando a favo.

Ao lusco-fusco, quanta alegria!

A meninada toda acorria

Para cantar, no mesmo terreiro:

"Mais bom dia, Vossa Senhoria”...

"Bom barqueiro! Bom barqueiro..."

Soava a canção pelo povoado inteiro

E a própria lua cirandava e ria.

Se a tarde de domingo era tranqüila,

Saía-se a flanar, em pleno sol,

No campo, recendente a camomila.

Alegria de correr até cair,

Rolar na relva como potro novo

E quase sufocar, de tanto rir!

No riacho claro, às segundas-feiras,

Batiam roupas as lavadeiras

Também a gente lavava trapos

Nas pedras lisas, nas corredeiras;

Catava limo, topava sapos

(Ai, ai, que susto! Virgem Maria!)

Do tempo, só se sabia

Que no ano sempre existia

O bom tempo das laranjas

E o doce tempo dos figos...

Longínqua infância... Três Barras

Plena de sol e de cigarras!

(KOLODY, 1999, p. 182)

Em Infância, a poetisa versa sobre sua infância em Três Barras (SC), mas junto das lembranças, lemos também a forma pela qual a escritora sente e enuncia a paisagem. Como considera Milton Santos, a paisagem "não é formada apenas por volumes, mas também de cores, movimentos, odores, sons [...]. A dimensão da paisagem é a dimensão da percepção, o que chega aos sentidos" (SANTOS, 1996, p.61-62). Desta forma, as regiões de memória constituídas por Helena nos chegam não apenas por meio das imagens e descrições visuais, mas pelas sensações e percepções que os diferentes sentidos de seu corpo captam e buscam reproduzir literariamente: o movimento das formigas, a aspereza dos troncos de pessegueiros, o zumbido das abelhas, o cheiro dos favos de mel... Por meio dos diferentes sentidos, a paisagem se completa e adquire significado, complexificando os vínculos culturais e afetivos com os lugares, estabelecendo e construindo um sentido topofílico para as paisagens.

Nossa viagem pelas paisagens de Helena Kolody, pelas regiões de memória presentes em sua primeira poética, buscará organizar este mosaico sensorial paisagístico, estabelecendo relações entre os elementos da paisagem e os significados atribuídos subjetiva e culturalmente pela autora. Para tanto, o percurso será composto por diferentes paradas, todas elas complementares na paisagem, porém distintas na percepção do ambiente: experiências táteis, sonoras, odoríferas e visuais.

\section{Pinheirais IMigrantes, eStePes IMAgINÁRIAS}

Eu desço na estação do trem: é década 1940. Curitiba, apesar de periférica em termos de Brasil, crescia em gente e concreto, urbanizava-se de forma intensa e acelerada, 
em medida suficiente para que uma reação cultural à modernização da cidade tomasse corpo sob a forma de um modernismo literário e artístico. É em 1940 que Dalton Trevisan iniciou seu combate ao provincianismo paranista na revista Joaquim, expondo nacionalmente as fragilidades do cenário cultural do Paraná. Nesta mesma década, nesta mesma revista, o escritor curitibano cantou a Curitiba sem pinheiros, a Curitiba que não é aquela para inglês ver. A capital paranaense crescia, e seus limites e fronteiras diluíam no mesmo compasso, atualizando a produção intelectual do estado com os grandes centros do Brasil e do mundo. Mas a Curitiba sem pinheiros, a cidade de Trevisan, não é a mesma de Helena Kolody.

Se o modernismo paranaense representado pela militância estética de Joaquim combateu o simbolismo e o paranismo que dominavam a cena cultural local de Curitiba, Helena Kolody, mesmo que do ponto de vista formal possa ser considerada uma escritora moderna, dialogou intensamente com tais correntes intelectuais. Distante das polêmicas, a poetisa construiu sua obra pelas margens, sem alarmes, sem excessos, versando silenciosa sobre a natureza, a infância, a transcendência e a vida interior. Curitiba crescia, mas não eram os prédios nem a vida cotidiana do povo simples da capital que a interessavam. Sua cidade era outra: era espelho, reflexo da luz que emanava de seu ser. Assim, quando foi moderna, Helena foi moderna de um jeito só seu, sob a influência das tendências estéticas que pairavam na realidade de seu Estado, com os anseios e atavismos de uma filha de imigrantes ucranianos, cheia de uma bagagem subjetiva bastante peculiar.

Em Paisagem Interior, o paranismo do início do século XX transparece no poe- ma Araucária, denunciando suas conexões orgânicas com a intelectualidade local do período. Eleito pelos paranistas como símbolo máximo do Estado, a imagem poética da araucária criada por Helena faz eco aos elogios e às exaltações do pinheiro por parte dos escritores e artistas plásticos ligados ao movimento:
Araucária, Nasci forte e altiva, Solitária.
Ascendo em linha reta
- Uma coluna verde-escura
No verde cambiante da campina.

Estendo braços hirtos e serenos.

Não há na minha fronde

Nem veludos quentes de folhas, Nem risos vermelhos de flores, Nem vinhos estonteantes de perfumes. Só há o odor agreste da resina, E o sabor primitivo dos frutos.

Espalmo a taça verde no infinito. Embalo o sono dos ninhos Ocultos em meus espinhos. $\mathrm{Na}$ silente nudez do meu isolamento. (KOLODY, 1999, p. 213)

As associações características do paranismo também estão lá: forte $\mathrm{e}$ altivo, o pinheiro é o gigante que estende os braços ao infinito, acolhedor e amigo. Em meio aos espinhos, o pinheiro dá abrigo aos passarinhos, é o amigo que embala o sono dos ninhos. Diversa, apenas a imagem da araucária 
solitária e quase entristecida: sem os veludos das folhas, sem os risos e perfumes das flores, árvore melancólica, de uma seriedade de "coluna verde-escura". Em suas primeiras obras, os pinheiros e pinheirais ainda vão aparecer em inúmeros poemas, não mais como personagem que rouba a cena, mas compondo a paisagem com sua força simbólica. Helena dava um passo para a literatura moderna, alocando os pinheiros na paisagem e deixando gradualmente em suspenso (mas não abandonando por completo) a exaltação romântica, lírica e simbolista da árvore-símbolo - impulso tipicamente paranista.

Em Dor, os pinheiros voltam a compor a paisagem acompanhados dos carvalhos - espécie típica das florestas do leste europeu, elemento fundamental de algumas das mitologias europeias e eslavas. $O$ incêndio de inverno na floresta, quando o "fogo tisna o tronco dos carvalhos/consome as frondes dos pinheiros", é comparado à dor do eu-lírico:

Gemeu

E estalou

No paroxismo;

Os pinheiros arderam como tochas

Até o fim.

Só ficou uma lápide de cinzas,

Porque a minha dor é a destruição total.

(KOLODY, 1999, p. 232)

Com a junção poética de duas espécies extremamente simbólicas - a araucária e o carvalho - em uma mesma paisagem, Helena Kolody exprime a dor por meio de uma quei- mada na qual os símbolos de sua terra ancestral e de sua terra natal são dizimados pelo fogo. Nesta passagem, como em outras que serão ainda motivo de atenção, a escritora conecta duas realidades geográficas distintas (Europa e Brasil, mais precisamente o Paraná), criando o vínculo estético que dá sentido à sua subjetividade imigrante e estabelecendo no imaginário uma associação da paisagem - e, portanto, da cultura e da natureza - paranaense com a Europa ancestral do imigrante. Tais conexões se verificam em inúmeros poemas dos livros aqui analisados, nas mais variadas formas de ligação poética/paisagística entre o Paraná e a Europa.

Em Atavismo, as mencionadas conexões são realizadas de forma mais explícita. Do próprio título - nome que se refere às semelhanças com antepassados - às imagens construídas, o poema é uma confissão de cumplicidade da escritora com suas origens ancestrais ucranianas, mesmo que sua ligação seja necessariamente moldada pela cultura trazida pela família e pela comunidade imigrante ucraniana vinda para o Brasil. Consciente de seu desligamento objetivo com o continente europeu - Helena nunca pôde visitar sua pátria eslava -, a poetisa versou:

Pois até o marulhar misterioso e sombrio Da água escura a correr seu destino de rio, Lembra, sem o querer, numa impressão falaz,

O soturno Dnipró, cantado por Taras... (KOLODY, 1999, p. 216)

Aqui, Helena Kolody faz referência ao poeta máximo do romantismo ucraniano, 
Taras Chevtchenko, cuja obra é sempre relembrada pela escritora como um de seus primeiro contatos com a literatura e a poesia. Declamado por seus pais, os versos de Chevtchenko funcionaram em Helena como elo com a cultura letrada ucraniana, e, consequentemente, como repertório paisagístico que se agrega ao seu mural de elementos estéticos/naturais presentes nas imagens e descrições de sua poética. Deste modo, referenciais tipicamente europeus são introduzidos na paisagem da escritora, deliberadamente ou não, recriando a cultura paranaense e seu imaginário natural e paisagístico. Este processo se verifica igualmente no caso das estepes, planícies típicas do leste europeu onde a vegetação é baixa e a paisagem se caracteriza pela ausência de árvores de grande porte:

Ante a extensão agreste e verde da campina,

Não sei dizer por que, muitas vezes, senti Saudade singular da estepe que não vi. (KOLODY, 1999, p. 216)

Em Atavismo, a estepe surge como referência consciente à realidade geográfica da Ucrânia. Em outros momentos, contudo, as estepes voltam a surgir nos textos poéticos de Helena de forma metafórica, relacionando-se à realidade interior da escritora (não é aleatória a escolha do título de sua primeira obra, Paisagem Interior), e, portanto, vinculando-as à natureza de seu ser, dotando a paisagem de um status mais elevado, mais próximo, conhecido esta estepe como estepe efetivamente vis- ta. Após considerar sua alma uma esfinge eslava, o eu-lírico de Perspectiva nos informa de que, em seus olhos, pode ser encontrada, numa paisagem agreste, a estepe soberana.

E para que não pise a estepe imaculada O duro sapatão de algum mujique alvar, $\mathrm{Eu}$ ando sempre alerta e trago bem guardada

A paisagem de neve oculta em meu olhar. (KOLODY, 1999, p. 219)

Assim, novamente Helena frisa a presença europeia dentro de si mesma, e, com isso, objetiva a paisagem ucraniana na realidade paranaense, já que ela mesma faz parte desta nova sociedade, e as estepes, os mujiques, as paisagens de neve, carregadas dentro de sua subjetividade imigrante, podem ser vistas também aqui, por meio de seu olhar. Pode-se mesmo considerar que, para além dos limites da poética de Kolody e do imaginário imigrante do brasileiro-ucraniano, as estepes se tornaram uma imagem presente na cultura e no imaginário paisagístico paranaense do período (quantas gerações teriam sido influenciadas?), como nos sugere construção semelhante em poema de Brasil Pinheiro Machado, no qual o poeta ponta-grossensse afirma: "Os campos eram longos e tristes como as estepes da Rússia" (MACHADO, 2001, p. 23). Não só as estepes e a analogia com o leste europeu lembram a poética kolodyana, mas também a tristeza e a melancolia associadas aos elementos naturais - como no caso da araucária solitária de Helena. 
AS ESTAÇÕES DO ANO, OS FENÔMENOS CLIMÁTICOS, AS FASES DO DIA

Nas regiões de memória da poética kolodyana, o tempo não se mede pelos relógios ou calendários, e a distribuição das fases do dia, das estações do ano e dos fenômenos climáticos responde ao repertório subjetivo da escritora. Deste modo, é possível perceber que por estas bandas, faz mais frio do que calor, há mais inverno que verão, as manhãs de bruma são mais longas do que as tardes ensolaradas, e mesmo quando as nuvens fogem e o sol aparece, é sempre sol de outono, quase nunca chega o verão. Os títulos, antes mesmo dos versos, revelam as ênfases: o inverno surge nas Rosas de Inverno e na Canção de Inverno, o outono em Prenúncio de Outono e Paisagem de Outono e o período da manhã é evocado em Matinal e Canção da Manhã.

Nas constantes referências ao frio mais características do que as alusões ao calor -, é possível perceber o cruzamento e a mescla entre as paisagens do centro-sul paranaense e as lembranças apropriadas de uma Europa que a autora nunca pôde visitar fisicamente. Neste sentido, o repertório imigrante de sua família ucraniana se faz sentir quando Helena anuncia que “ao primeiro prenúncio das geadas/ [...] / as roseiras sem flor/ [...] /são monjas medievais ensimesmadas", ou ainda que "na bruma do cenário matutino/o coração virente da floresta/lembra um antigo templo bizantino"10. Tais associações, como já enfatizado, reforçam o sentido de sua identidade imigrante e encurtam as distâncias entre suas diferentes facetas.

9 Trecho de Rosas de Inverno (KOLODY, 1999, p. 201). 10 Trecho de Matinal (Idem, p. 200).
Dentre os elementos paisagísticos da poética de Kolody, dois deles podem exemplificar e ilustrar sua propensão subjetiva às baixas temperaturas: a neve e a geada. Esta última aparece como elemento de ambientação em inúmeros poemas da autora. Enfatizando o frio das madrugadas paranaenses, Helena versa em Imigrantes Eslavos:

Cabeça branca do neto,
Cabeça branca do avô.
Luar noturno e geada,
Que é orvalho da madrugada.
(KOLODY, 1999, p. 178)

Do mesmo modo, em Rosas de Inverno (KOLODY, 1999, p. 201), a luz esmorece no fim do outono, no primeiro prenúncio das geadas. Novamente é possível comparar os elementos paisagísticos da poética kolodyana com os de Brasil Pinheiro Machado, que em 1928 já anunciava um sol que "pisca-piscava no céu sem derreter o friozinho gostoso da geada" (MACHADO, 2001, p. 23).

Se a geada é um fenômeno climático característico dos invernos paranaenses ao menos no que se refere à região CentroSul, a qual Helena viveu de forma mais intensa -, não se pode afirmar o mesmo das nevascas. Bastante raras, as nevascas no Estado do Paraná ocorrem com mais regularidade na região de Palmas, sudoeste paranaense. Na região de Curitiba, por exemplo, as precipitações de neve foram registradas oficialmente na média de uma vez a cada dez anos. ${ }^{11}$ Mas a raridade do fenômeno não

11 Segundo dados da Secretaria do Turismo do Paraná, as precipitações ocorreram nos anos de 1889, 1892, 1912, 1928 (dois dias), 1943, 1955, 1957, 1963, 1975, 1979, 1981 e 
possui paralelo nas regiões poéticas de memória kolodyanas. Nelas, a neve é bastante presente como realidade interior, e desta forma se integra à paisagem cultural que a poetisa constrói.

Em Canção de Inverno (KOLODY, 1999, p. 170), a neve cai de mansinho nos cabelos do eu-lírico, em seu rosto, para na última estrofe do poema este se perguntar: "Será neve resvalando/Ou é pranto a deslizar?". Novamente, uma espécie de melancolia - representada pelo pranto - se associa ao frio, e o frio, como elemento constante na poética da autora, se associa às paisagens evocadas. A ligação entre o frio e a tristeza - desta vez em alusão ao clima europeu - também é enfatizada em outros de seus poemas, como em Edelweiss (KOLODY, 1999, p. 194). Nome dado a uma flor que nasce nos Alpes europeus, Edelweiss é, para Helena, uma "frágil flor da neve! [...] Triste flor do amor!" E se os Alpes e as flores encontradas nos cimos de suas montanhas aparentemente nada possuem de semelhança ou relação com a realidade paranaense, uma outra flor, também cravada no alto de uma montanha, é sonho e desejo do homem nativo das redondezas do Marumbi: se ele "escalasse aquele pico sobranceiro" poderia colher uma "serena flor azul do céu da tarde" (KOLODY, 1999, p. 202).

Sutilmente, Helena Kolody emprega imagens, metáforas, paisagens, e mesmo histórias e lendas que compõem o imaginário da escritora, em poemas que tratam de duas nações: pátria natal e pátria ancestral, Brasil e Europa, Paraná e Ucrânia. Mas na memória, traduzida poeticamen-

1988.http://www.turismo.pr.gov.br/modules/conteudo/ conteudo.php? conteudo $=207$ - Site Oficial da Secretaria Estadual do Turismo do Paraná - acessado em 19 de fevereiro de 2013. te nas obras aqui analisadas, os lugares se confundem, tornam-se um só. As paisagens de Helena formam uma região de memória, um espaço que é antes cultural do que natural. Esta região pode ser compartilhada por meio de versos, e uma vez captada pelo leitor de poesia, se espalha ignorando fronteiras, formando o caldo cultural com o qual as gerações podem se alimentar. Na construção identitária do paranaense, os contornos e os quadrantes dados à realidade por Helena Kolody estão também presentes, direta ou indiretamente, por ação espontânea ou promovida pelo Estado. Assim, as paisagens da poética kolodyana se excedem, surgem noutros horizontes, tornam-se paisagens paranaenses.

\section{Considerações Finais}

Nem sempre a imagem que fazemos de determinados lugares condiz com a realidade. De fato, o mais correto é que a relação seja inversa: as memórias de lugares e paisagens que, por meio de diferentes linguagens, recriamos, são produtos de nossa sensibilidade e de nosso filtro cultural e subjetivo da percepção. Falar das paisagens, portanto, é mergulhar em nossa cultura, tornando-nos mais conscientes sobre nossa própria identidade.

Pela análise empreendida, busquei mapear as regiões de memória de Helena Kolody, levando em consideração que as relações estabelecidas entre os sujeitos e o espaço são construídas a partir de múltiplas referências sensoriais e perceptivas, e, deste modo, a temperatura, os cheiros, os sons que brotam dos poemas são também parte deste ambiente literário que efetivamente se (re)produz pela 
ênfase que nosso filtro cultural pode criar em determinadas características espaciais.

Mas são caminhos subterrâneos e sutis aqueles que levam as imagens dos poemas para a memória dos sujeitos. Quando pequeno, participei de incontáveis atividades de leitura e declamação de poesia. Não me recordo dos versos que eu lia e escutava na escola. Mas me lembro da professora que os entregava a mim. A ela, que nunca pude agradecer pelo incentivo à escrita e à leitura, devo alguma gratidão, já que os ecos poéticos daquele tempo ainda estão soando em minha mente, mesmo que sem querer. Quando fui apresentado à poesia de Helena Kolody, eu não tinha consciência do poder daquelas estrofes, nem fazia ideia do quanto aquelas leituras me (de)formariam. Hoje, quando pego um livro de poemas que é de Helena, lembro-me da professora, mas me lembro também de uma região que só desbravo pela literatura, região que, apesar de imaginária, é também meu lar.

\section{REFERÊNCIAS}

BACHELARD, G. A poética do espaço. Rio de Janeiro: Eldorado, 1989.

BOURDIEU, P. A identidade e a representação: elementos para uma reflexão crítica sobre a ideia de região. In: $\mathbf{O}$ poder simbólico. 4. ed. Rio de Janeiro: Bertrand Brasil, 2001.

CERTEAU, M. de. A invenção do cotidiano: 1. Artes de fazer. 17.ed. Petrópolis: Vozes, 2011. COSGROVE, D. Social formation and symbolic landscape. Madison: University of Wisconsin Press, 1998.

CRUZ, A. D. Helena Kolody: a poesia da inquietação. Dissertação de mestrado. Porto Alegre, PUC Rio Grande do Sul, 1993.
O universo imaginário e o fazer poético de Helena Kolody. Tese de Doutorado em Literatura Brasileira - Instituto de Letras da Universidade Federal do Rio Grande do Sul, Porto Alegre, 2001.

FILHO, A. C. Q. Saboreando o espaço, inventando paisagens. Paisagens em debate: revista eletrônica da área de Paisagem e Ambiente, FAU USP, n. 05, dezembro, 2007. FONTES, L. C. dos S. A terra estrangeira de Helena Kolody. Graphos (João Pessoa), v. 9, 2007, p. 167-179.

- Quando Helena Kolody cruzou a fronteira. Estudos de literatura brasileira contemporânea, n.32. Brasília, julhodezembro de 2008, p.161-172.

KARNAL, L. (Org.). História na sala de aula: conceitos, práticas e propostas. São Paulo: Contexto, 2012.

KOLODY, H. Viagem no espelho. 5. ed. Curitiba: Editora da UFPR, 1999.

MACHADO, B. P. Poemas seguidos de dois ensaios. Curitiba: Imprensa Oficial do Paraná, 2001.

MORIN, E. Os sete saberes necessários à educação do futuro. São Paulo: Cortez; Brasília, DF: UNESCO, 2000.

OLIVEIRA, L. C. S. de. Dalton Trevisan (en) contra o Paranismo. Curitiba: Travessa dos Editores, 2009.

SANTOS, M. Metamorfose do espaço habitado. São Paulo: Hucitec, 1996.

SCHAMA, S. Paisagem e memória. São Paulo: Companhia das letras, 1996.

SOARES, M. C. Helena Kolody: uma voz imigrante na poesia paranaense. Dissertação de Mestrado. Universidade Estadual de Campinas, Campinas, 1997.

Entre dois mundos: a poesia de imigração de Helena Kolody. In: Luísa Cristina dos Santos. (Org.). Literatura e mulher: das 
linhas às entrelinhas. Ponta Grossa: Editora da UEPG, 2002, p. 105-120.

STEFANELLO, A. C. Didática e avaliação da aprendizagem no ensino de geografia.

Curitiba: Ibpex, 2011.

VIEIRA, D. de S. L. Paisagem e imaginário: contribuições teóricas para uma história cultural do olhar. Fênix - Revista de História e Estudos Culturais. v. 3, n.3, julho/ agosto/ setembro 2006.

Recebido para publicação em $1^{\circ}$ abr. 2013. Aceito para publicação em $30 \mathrm{dez} .2013$. 